\title{
Concept mediation in trilingual translation: Evidence from response time and repetition priming patterns
}

\author{
WENDY S. FRANCIS and SABRINA L. K. GALLARD \\ University of Texas, El Paso, Texas
}

\begin{abstract}
Translation responses to individual words were elicited from 48 English-Spanish-French trilinguals, who translated in six directions at study and two directions at test. Patterns of translation response times and error rates at study reflected the relative proficiency of the trilinguals in comprehension and production of their three languages. At test, repeated items were translated more quickly than new items, with the strongest priming effects occurring for identical repetitions. Repetition priming was also substantial when only the stimulus language or only the response language matched from study to test, implying that repeated comprehension and production processes contribute to priming in translation. Patterns of response times and repetition priming indicate that translation in all directions involved conceptual access. Additive patterns in response time asymmetries and repetition priming were consistent with the treatment of word comprehension and production processes of translation as independent.
\end{abstract}

Word translation is an inherently bilingual task, in that a stimulus in one language elicits a response in another language. Cognitive research on translation has focused on the mental processes that occur between the stimulus and the response and on how they change with language exposure and proficiency. Two routes for translation have been proposed. In concept-mediated translation, the stimulus word is comprehended (the concept or meaning is accessed) before production (retrieval and articulation) of the response word, but in word-mediated translation, corresponding words are retrieved directly, without conceptual access (Potter, So, von Eckardt, \& Feldman, 1984).

Researchers agree that in fluent bilinguals, translation from the more fluent to the less fluent language is concept mediated, but they continue to debate whether translation from the less fluent to the more fluent language is concept mediated (e.g., de Groot, Dannenburg, \& van Hell, 1994; de Groot \& Poot, 1997; Francis, Augustini, \& Sáenz, 2003; La Heij, Hooglander, Kerling, \& van der Velden, 1996) or word mediated (e.g., Kroll \& Stewart, 1994; Sholl, Sankaranarayanan, \& Kroll, 1995). Response times (RTs) are similar for the two translation directions in balanced bilinguals (e.g., Francis et al., 2003; Potter et al., 1984), but in less fluent bilinguals, translation to the dominant language is usually faster (e.g., Kroll \& Stewart, 1994;

This project was supported by National Institutes of Health Grant MH61765. S.L.K.G. completed the study as a senior honors thesis. We thank Ken Forster, Judith Kroll, and Annette de Groot for their insightful comments on the manuscript. S.L.K.G. is now in the Faculté de Psychologie et des Sciences de l'Education at the Université Catholique de Louvain, Louvain-la-Neuve, Belgium. Address correspondence to W. S. Francis, Department of Psychology, University of Texas, El Paso, TX 79968 (e-mail: wfrancis@utep.edu).
Sholl et al., 1995; but see de Groot \& Poot, 1997), an effect first reported by James McKeen Cattell in the 1880s (Cattell, 1887/1947). One explanation is that bilinguals use two different translation routes, with concept-mediated translation to the nondominant language and word-mediated translation to the dominant language (Kroll \& Stewart, 1994; Sholl et al., 1995). An alternative explanation is that translation is concept mediated in both directions but that proficiency has stronger effects on production than on comprehension and, therefore, the net effect favors translation to the dominant language (Snodgrass, 1993).

Whereas bilinguals translate in two directions, trilinguals can translate in six directions (see Table 1). In the present trilingual study, translation RTs and error rates were measured for unpracticed items in all six directions. Having more translation directions than languages makes a more thorough elucidation of the component cognitive processes possible. As is shown in Figure 1, comparisons can be made among translation directions with the same stimulus language or the same response language, thereby isolating the source of differences in RTs or error rates. For example, if English-French (EF) translation takes longer than English-Spanish (ES) translation, the difference can be attributed to a difference between French and Spanish production time. Trilingual experiments eliminate individual difference confounds inherent in comparing groups of more and less proficient bilinguals, as has been pointed out by de Groot and Hoeks (1995), because critical comparisons can be made with different pairs of languages within individuals. For example, one trilingual study showed an advantage for concrete over abstract words in Dutch-English translation, suggesting concept mediation; in contrast, Dutch-French translation did not show this effect, suggesting word mediation (de 
Table 1

Mean Translation Response Times (RTs, in Milliseconds) and Error Rates (in Percentages) in the Study Phase

Translation Direction (Stimulus-Response)

English-French French-English Spanish-French French-Spanish English-Spanish Spanish-English

$\begin{array}{cc}\text { RT } & \text { Error Rate } \\ 1,679 & 24.2 \\ 1,490 & 16.4 \\ 1,770 & 33.0 \\ 1,588 & 25.2 \\ 1,303 & 15.6 \\ 1,303 & 10.6\end{array}$

Groot \& Hoeks, 1995). Translation RTs ought to reflect relative proficiency, as was found in a study with ArabicHebrew-English trilinguals (Abunuwara, 1992).

Translation exhibits substantial repetition priming, with faster responses for repeated items than for new items (Francis \& Sáenz, 2004; Francis, Tokowicz, \& Kroll, 2004) even after a 1-week retention interval (Francis \& Sáenz, 2004). According to the principle of transferappropriate processing (Morris, Bransford, \& Franks, 1977; Roediger \& Blaxton, 1987), the strength of a repetition effect depends on the match between cognitive processes at study and test. Indeed, even partial matches between processes at study and test elicit priming in translation. For example, picture naming facilitates later translation, because of repeated word production processes (Francis et al., 2003; Sholl et al., 1995).

In the present trilingual study, different translation directions at study were chosen in order to facilitate selectively the word comprehension and word production processes of concept-mediated translation at test. As is illustrated in Figure 1, translation directions that have the same stimulus language share word comprehension processes, and directions that have the same response language share word production processes. Therefore, translating words from one stimulus language to different

A. Shared Word Comprehension

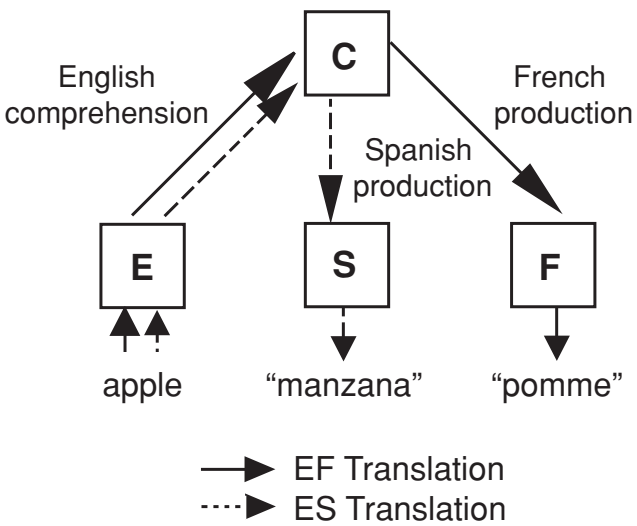

response languages should facilitate word comprehension processes. Similarly, translating from different stimulus languages to the same response language should facilitate word production processes.

Translation from the most fluent language (English) to the least fluent language (French) was expected to be concept mediated, as in bilinguals. We therefore predicted that both ES and Spanish-French (SF) translation would facilitate later EF translation, because of shared comprehension processes (in the case of ES) and shared production processes (in the case of SF). Including repetition conditions with final French-English (FE) translation allowed a test of the route for translation from the least fluent to the most fluent language. If $\mathrm{FE}$ translation is word mediated, it should exhibit little or no priming based on prior French-Spanish (FS) translation, because word comprehension processes would not be shared. Similarly, word-mediated FE translation would not be substantially facilitated by prior SE translation, because only articulation processes would be shared, in accord with the lack of priming from picture naming to translation observed in Sholl et al.'s (1995) study. However, under concept-mediated translation, priming would be substantial, as with the priming from picture naming to translation observed in Francis et al.'s (2003) study.

\section{METHOD}

\section{Participants}

The participants were 48 English-Spanish-French trilingual adults (13 men and 35 women), recruited at the University of Texas at El Paso and in the community and paid $\$ 10$. The median age was 36 years $(S D=17)$. Two additional participants were excluded from analysis and were replaced because of poor performance. On the basis of a language background questionnaire, 29 had learned Spanish first, 12 had learned English first, and 7 had learned French first. Mean ages of acquisition were 5.6 years for Spanish, 6.7 for English, and 13.3 for French. The self-reported dominant language was Spanish for 23 participants, English for 21, French for 3, and both English and Spanish for 1; 42 participants were more fluent

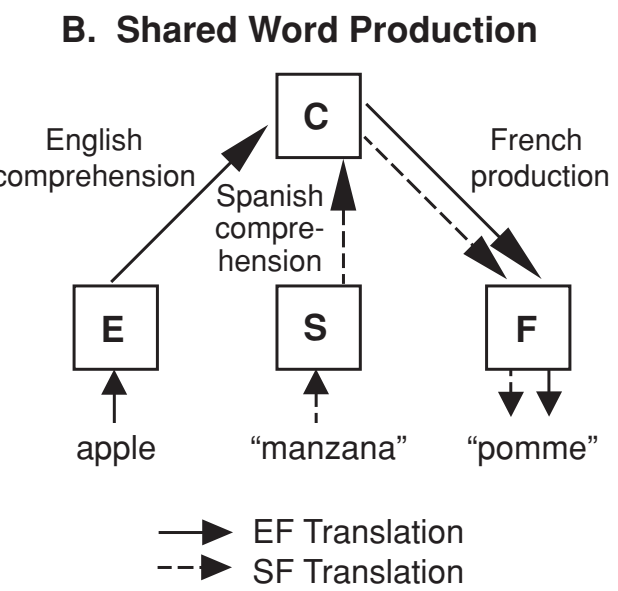

Figure 1. Processes in concept-mediated translation. (A) English-Spanish (ES) and English-French (EF) translation share English word comprehension processes. (B) Spanish-French (SF) and EF translation share French word production processes. $\mathrm{C}$, concept; quotation marks indicate overt responses. 
in English than in French, 33 were more fluent in Spanish than in French, and 27 were more fluent in English than in Spanish. The participants reported their usage of the languages over the preceding month as 50.4\% English, 30.2\% Spanish, 10.4\% French, 8.3\% mixtures of these languages, and $0.7 \%$ other languages.

\section{Materials \\ The stimuli were 216 concrete nouns selected to be relatively unambiguous in meaning in English, Spanish, and French, avoid- ing items that had identical orthography in any two languages. The median Kučera and Francis (1967) frequency of the English stimu- lus words was 22 per million, and mean letter lengths were 5.7 for English, 6.3 for Spanish, and 6.5 for French. Items were randomly assigned to eight sets, with the assignment of sets to languages and conditions counterbalanced across participants.}

\section{Design and Procedure}

The participants were tested individually by a trilingual experimenter in sessions lasting approximately $50 \mathrm{~min}$. After a language background questionnaire had been completed, instructions for each block of translation trials were given in the assigned translation response language. The stimuli were presented on a Macintosh computer using PsyScope software (Cohen, MacWhinney, Flatt, \& Provost, 1993). The study phase had six translation blocks, one in each of the six possible directions (ES, EF, FE, FS, SE, and SF), with the order counterbalanced across participants. Each block had 3 practice trials and 27 experimental trials (in random sequence), with an interval of $1,250 \mathrm{msec}$ between registration of a response to 1 item and the presentation of the next item. The test phase had two blocks of 108 trials, one for EF translation and one for FE translation, with the order of blocks counterbalanced. Within each test block, 27 items were new, 27 had previously been translated in the same direction, 27 had previously been translated from the stimulus language to Spanish, and 27 had previously been translated from Spanish to the response language. These four sets were intermixed using block randomization. Vocal responses were timed using a PsyScope button box (New Micros, Dallas). Unexpected responses and voice relay misfires were recorded.

\section{RESULTS}

\section{Patterns of Performance Across Six Translation Directions}

Unpracticed translation performance was compared across languages, using the study phase data. RT analyses were performed on condition means for correct and validly timed translation responses, with outlier trials removed (i.e., those having RTs that were $<200 \mathrm{msec}$, $>5,000 \mathrm{msec}$, or further than $2 \mathrm{SD}$ s from the condition mean). Mean RTs and error rates are given in Table 1. A comparison of performance across opposite directions of translation showed effects consistent with previous bilingual findings. For languages with very different proficiency levels, RTs were substantially longer and error rates were higher when the participants responded in the less fluent language. Thus, EF translation had longer RTs than did FE translation $\left[t_{1}(47)=2.84, p=.007\right.$; $t_{2}(417)=3.194, p=.002 ; \min F^{\prime}(1,356)=4.50, p=$ $.035]$ and higher error rates $\left[t_{1}(47)=5.22, p<.001\right.$; $t_{2}(422)=4.27, p<.001 ; \min F^{\prime}(1,424)=10.92, p=$ $.001] .{ }^{1}$ Similarly, SF translation had longer RTs than did FS translation $\left[t_{1}(47)=2.37, p=.022 ; t_{2}(397)=2.95\right.$, $\left.p=.003 ; \min F^{\prime}(1,283)=3.41, p=.066\right]$ and higher error rates $\left[t_{1}(47)=3.09, p=.003 ; t_{2}(422)=4.52, p<\right.$ $\left..001 ; \min F^{\prime}(1,426)=6.51, p=.011\right]$. These patterns are consistent with the translation asymmetries observed in previous studies with less balanced bilinguals (Francis et al., 2004; Kroll \& Stewart, 1994; Sholl et al., 1995). For languages of similar proficiency (English and Spanish), RTs for ES and SE translation were indistinguishable $\left[t_{1}(47)=0.01, p=.989 ; t_{2}(422)=2.91, p=.004 ; \mathrm{min}\right.$ $\left.F^{\prime}(1,222)=0.0002, p=.989\right]$, but error rates were higher when the participants translated to the less proficient language [Spanish; $t_{1}(47)=3.64, p=.0011 ; t_{2}(422)=$ $2.735, p=.007$; $\left.\min F^{\prime}(1,424)=4.78, p=.029\right]$. This pattern is consistent with findings for relatively balanced bilinguals (Francis et al., 2003; Francis \& Sáenz, 2004; Francis et al., 2004). ${ }^{2}$

Having more translation directions than languages allowed several new comparisons. Comprehension differences (Figure 2) were estimated by comparing conditions that differed only in the stimulus language. FS translation took longer than ES translation $\left[t_{1}(47)=6.05, p<\right.$ $.001 ; t_{2}(410)=9.84, p<.001 ; \min F^{\prime}(1,371)=26.59$, $p<.001]$ and had a higher error rate $\left[t_{1}(47)=5.88, p<\right.$ $.001 ; t_{2}(422)=3.36, p=.001 ; \min F^{\prime}(1,424)=8.50$, $p=.004]$, indicating that French comprehension was slower and less accurate than English comprehension. Similarly, a comparison of FE and SE translation indicated that French comprehension took longer than Spanish comprehension $\left[t_{1}(47)=3.11, p=.003 ; t_{2}(420)=\right.$ $\left.5.72, p<.001 ; \min F^{\prime}(1,268)=7.48, p=.007\right]$ and had a higher error rate $\left[t_{1}(47)=2.12, p=.039 ; t_{2}(422)=\right.$ $\left.3.01, p=.003 ; \min F^{\prime}(1,437)=3.01, p=.084\right]$. A comparison of SF and EF translation indicated numerically longer Spanish than English comprehension times, but this effect was not statistically reliable $\left[t_{1}(47)=1.36, p=\right.$ $.182 ; t_{2}(406)=1.23, p=.219 ; \min F^{\prime}(1,379)=0.83$, $p=.363]$; however, error rates were significantly higher for Spanish $\left[t_{1}(47)=3.59, p=.001 ; t_{2}(422)=3.37, p=\right.$ $\left..001 ; \min F^{\prime}(1,426)=6.03, p=.014\right]$.

Production differences (Figure 2) were estimated by comparing conditions that differed in the response language. A comparison of SF and SE translation showed that French production took longer than English production $\left[t_{1}(47)=6.26, p<.001 ; t_{2}(409)=10.22, p<.001\right.$; $\left.\min F^{\prime}(1,239)=28.47, p<.001\right]$ and had a higher error rate $\left[t_{1}(47)=7.14, p<.001 ; t_{2}(422)=10.99, p<.001\right.$; $\left.\min F^{\prime}(1,430)=35.84, p<.001\right]$. A comparison of EF and ES translation showed that French production took longer than Spanish production $\left[t_{1}(47)=3.94, p<.001\right.$; $t_{2}(419)=10.14, p<.001 ; \min F^{\prime}(1,176)=13.50, p<$ $.001]$ and had a higher error rate $\left[t_{1}(47)=2.15, p=.037\right.$; $t_{2}(422)=4.92, p<.001 ; \min F^{\prime}(1,435)=3.88, p=$ $.050]$. A comparison of FS and FE translation showed that Spanish production took longer numerically than English production, but the difference was not statistically reliable $\left[t_{1}(47)=1.22, p=.228 ; t_{2}(408)=1.80, p=.073 ; \mathrm{min}\right.$ $\left.F^{\prime}(1,228)=1.02, p=.313\right]$; however, error rates were higher for Spanish $\left[t_{1}(47)=3.41, p=.001 ; t_{2}(422)=\right.$ $\left.2.81, p=.005 ; \min F^{\prime}(1,427)=4.71, p=.031\right]$.

If these observed RT differences indeed reflect differences in comprehension and production times, certain 


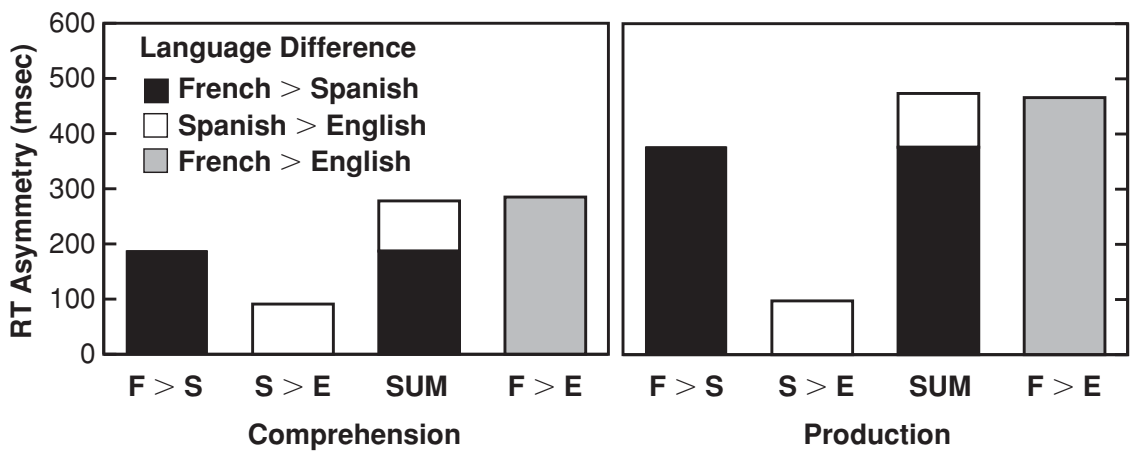

Figure 2. Derived estimates of asymmetries in comprehension and production time. The height of the leftmost bar indicates the difference between French and Spanish in comprehension time; the label F > S, for example, indicates that French took longer than Spanish. Sums of French-Spanish and Spanish-English differences are close to the corresponding French-English differences.

relations ought to hold. Specifically, the differences between French and Spanish and between Spanish and English ought to sum to the independently derived differences between French and English. In accord with this prediction, for comprehension, the difference between French and English (285 $\mathrm{msec})$ was comparable to the sum of the differences between French and Spanish and between Spanish and English $(187+91=278)$. Similarly, in production, the difference between French and English (466 msec) was comparable to the sum of the differences between French and Spanish and between Spanish and English $(376+97=473)$. These patterns indicate that translation was concept mediated in all directions, because word-mediated translation in any direction(s) would have caused a substantial deviation from this additive pattern. By comparison, application of the preceding derivations to the trilingual translation RTs reported by Abunuwara (1992) reveals a departure from this pattern, in accord with his conclusion that not all directions of translation were concept mediated in that population. (However, this comparison must be qualified by a procedural difference; in that study, 25 items were repeated for all 12 experimental tasks, and participant language background was not given in sufficient detail to compare with to the present sample.)

\section{Repetition Priming in Translation}

Test phase RTs were processed in the same manner as in the study phase, except that misprimed items (those with invalid study phase responses) were also excluded. Mean RTs are given in Table 2. As in the encoding phase, new-item RTs were longer for EF than for FE translation $\left[t_{1}(47)=3.74, p<.001 ; t_{2}(417)=2.10, p=.036\right.$; $\min$ $\left.F^{\prime}(1,456)=3.35, p=.068\right]$. Repetition priming was measured by subtracting repeated condition RTs from new-item RTs, and the priming effects are illustrated in Figure 3. Priming was substantial and statistically reliable in all six conditions $(p \mathrm{~s}<.05)$. As in research with bilinguals (Francis \& Sáenz, 2004; Francis et al., 2004), identical repetition priming was stronger when the participants responded in the less fluent language; specifically, identical repetition priming was stronger for EF than for FE translation $\left[t_{1}(47)=2.99, p=.004 ; t_{2}(409)=1.856\right.$, $\left.p=.064 ; \min F^{\prime}(1,438)=2.48, p=.116\right]$.

In identical translation repetition conditions, both word comprehension and word production processes can contribute to priming. Test phase RTs were submitted to a 2 (comprehension practiced) $\times 2$ (production practiced) $\times 2$ (final translation direction) repeated measures ANOVA. Practice of comprehension processes facilitated later translation $\left[F_{1}(1,47)=50.72, M S_{\mathrm{e}}=43,806, p<\right.$

Table 2

Translation Response Times (RTs) and Repetition Priming (in Milliseconds) in the Test Phase

\begin{tabular}{|c|c|c|c|c|}
\hline \multicolumn{2}{|c|}{ Direction } & \multirow{2}{*}{$\begin{array}{l}\text { Process(es) Repeated } \\
\text { From Study to Test }\end{array}$} & \multirow[b]{2}{*}{ RT } & \multirow[b]{2}{*}{ Priming } \\
\hline Study & Test & & & \\
\hline None & $\mathrm{EF}$ & - & 1,806 & - \\
\hline ES & $\mathrm{EF}$ & E comprehension & 1,695 & 111 \\
\hline SF & $\mathrm{EF}$ & F production & 1,382 & 424 \\
\hline EF & $\mathrm{EF}$ & E comprehension and $\mathrm{F}$ production & 1,251 & 555 \\
\hline None & FE & - & 1,625 & - \\
\hline FS & FE & F comprehension & 1,452 & 173 \\
\hline SE & FE & E production & 1,421 & 204 \\
\hline $\mathrm{FE}$ & FE & F comprehension and $\mathrm{E}$ production & 1,227 & 398 \\
\hline
\end{tabular}

Note-ES, English-Spanish; SF, Spanish-French; EF, English-French; FS, French-Spanish; SE, Spanish-English; FE, French-English. 


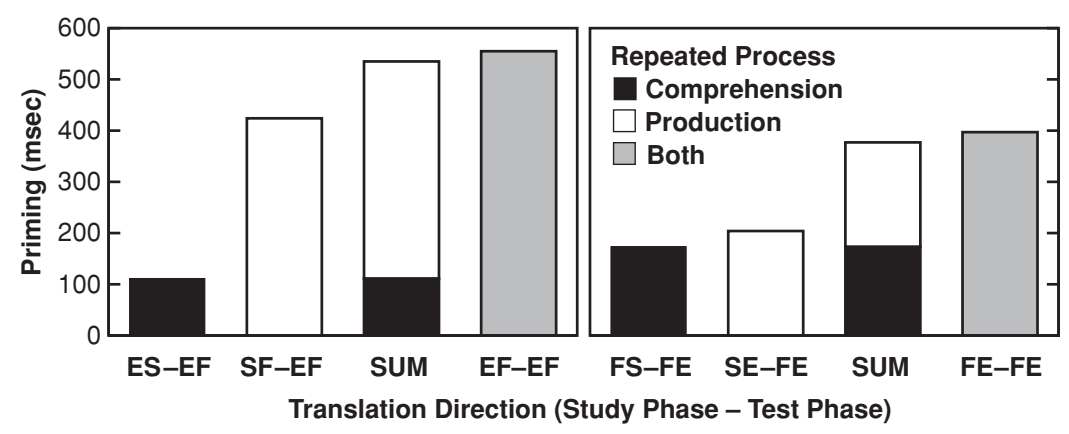

Figure 3. Repetition priming for comprehension, production, and identical conditions for English-French (EF) and French-English (FE) final translation. Sums of the comprehension and production effects are close to the corresponding identical repetition effects. New-item response times were 1,806 msec for $\mathrm{EF}$ and 1,625 msec for $\mathrm{FE}$ translation. SF, Spanish-French; SE, Spanish-English.

$.001 ; F_{2}(1,373)=38.05, M S_{\mathrm{e}}=190,678, p<.001 ; \mathrm{min}$ $\left.F^{\prime}(1,398)=21.74, p<.001\right]$. This comprehension priming was numerically stronger for French, but the corresponding interaction was not statistically significant $\left[F_{1}(1,47)=2.27, M S_{\mathrm{e}}=40,949, p=.139 ; F_{2}(1,373)=\right.$ $4.242, M S_{\mathrm{e}}=190,678, p=.04 ; \min F^{\prime}(1,403)=1.48$, $p=.22]$. Practice of production processes also facilitated later translation $\left[F_{1}(1,47)=150.69, M S_{\mathrm{e}}=67,040, p<\right.$ $.001 ; F_{2}(1,373)=177.56, M S_{\mathrm{e}}=185,818, p<.001 ; \min$ $\left.F^{\prime}(1,340)=81.51, p<.001\right]$. Production priming was stronger for French $\left[F_{1}(1,47)=14.79, M S_{\mathrm{e}}=78,083, p<\right.$ $.001 ; F_{2}(1,373)=22.78, M S_{\mathrm{e}}=185,818, p<.001 ; \min$ $\left.F^{\prime}(1,313)=8.97, p=.003\right]$. The effects of comprehension and production practice did not interact $\left[F_{1}(1,47)=\right.$ $0.22, M S_{\mathrm{e}}=44,805, p=.640 ; F_{2}(1,373)=10.53, M S_{\mathrm{e}}=$ $\left.172,506, p=.001 ; \min F^{\prime}(1,386)=0.22, p=.64\right]$. As is illustrated in Figure 3, priming of English comprehension from ES translation and priming of French production from SF translation added up to $96 \%$ of the priming obtained with identical EF translation. Similarly, priming of French comprehension from FS translation and priming of English production from SE translation added up to $95 \%$ of that obtained with identical FE translation.

Planned comparisons among partial-match conditions were made using a 2 (process practiced) $\times 2$ (process language) repeated measures ANOVA. Priming was stronger overall for production than for comprehension processes $\left[F_{1}(1,47)=39.92, M S_{\mathrm{e}}=35,675, p<.001 ; F_{2}(1,378)=\right.$ $19.73, M S_{\mathrm{e}}=230,998, p<.001 ; \min F^{\prime}(1,423)=13.20$, $p<.001]$, and French processes were primed more than English processes $\left[F_{1}(1,47)=11.08, M S_{\mathrm{e}}=85,835\right.$, $p=.002 ; F_{2}(1,378)=25.95, M S_{\mathrm{e}}=616,819, p<.001$; $\left.\min F^{\prime}(1,424)=7.76, p=.006\right]$. These findings support the idea that more difficult processes benefit more from repetition (Francis et al., 2003). The priming advantage for French was numerically stronger for production than for comprehension, but this interaction was not statistically significant $\left[F_{1}(1,47)=2.67, M S_{\mathrm{e}}=111,619, p=\right.$ $.109 ; F_{2}(1,378)=21.79, M S_{\mathrm{e}}=230,998, p<.001 ; \min$ $\left.F^{\prime}(1,289)=2.38, p=.124\right]$.

\section{DISCUSSION}

RTs and error rates followed a systematic pattern consistent with the participants' self-reported proficiency, language exposure, and recent usage. This pattern held in estimates of both comprehension and production differences across languages. The relative RTs fit a model in which translation includes conceptual access for all directions and comprehension and production are independent processes. Patterns of performance for translation in opposite directions with different combinations of the trilinguals' three languages showed that the translation asymmetry varied with the proficiency gap between the two languages involved. Therefore, the existence or degree of translation asymmetry often observed with unbalanced language proficiencies does not imply that the two directions involve qualitatively different processes.

Translation in both directions was facilitated by prior word comprehension in the stimulus language and by prior word production in the response language. Both findings contradict the interpretation that FE translation was word mediated. If the only shared processes were perception of the word form and articulation of the response, an upper limit on the expected magnitude of priming would be that obtained with repeated word reading - about $30 \mathrm{msec}$ (see, e.g., Durso \& Johnson, 1979). Priming in every partial repetition condition far exceeded this limit. Furthermore, because the partial repetition effects summed to $95 \%$ of the facilitation observed with identical repetition, a word mediation interpretation would imply that the process of accessing one translation equivalent from another was not facilitated. Therefore, the repetition priming results also indicate that translation was concept mediated.

The conclusion that translation was concept mediated converges with previous findings from balanced bilinguals but is inconsistent with some conclusions drawn from unbalanced bilinguals. The discrepancy may be explained in part by the different methods used to assess the route used for second-language-first-language (L2-L1) translation. The asymmetry in translation RTs across languages 
has itself been interpreted as evidence for word mediation, but the present results support Snodgrass's (1993) explanation that translation is concept mediated but the production asymmetry is stronger than the comprehension asymmetry. The greater magnitude of the translation RT asymmetry, relative to the word-naming asymmetry (e.g., Kroll \& Stewart, 1994; Potter et al., 1984), has also been interpreted as evidence of word mediation. However, picture naming is a more appropriate comparison task, because it requires the accessing of phonology on the basis of the concept; RT asymmetries for translation are typically smaller than those for picture naming (e.g., Francis et al., 2003; Potter et al., 1984; Sholl et al., 1995), a difference inconsistent with word mediation. Word mediation has also been employed to explain why categorizing sequences of L2-L1 translation trials did not interfere with performance (Kroll \& Stewart, 1994). However, a stronger manipulation involving presentation of semantically related distractors did elicit semantic interference (Miller \& Kroll, 2002), and simultaneous presentation of congruent pictures facilitated translation (La Heij et al., 1996); both results support concept mediation. In accord with this interpretation, word characteristics such as concreteness are correlated with translation performance in both directions (de Groot et al., 1994), even in beginning L2 learners (de Groot \& Keijzer, 2000).

The most compelling evidence of word mediation in fluent bilinguals has been that picture naming in L1 did not prime L2-L1 translation in late bilinguals who were highly dominant in L1 and living in an L1 context (Sholl et al., 1995). However, the effect was substantial in a later study with more balanced bilinguals living in a bilingual context (Francis et al., 2003). The samples may have used different translation routes, or priming may have been undetectable in the first study (e.g., because of less difficult items or stronger L1 dominance).

The present study was a first step in examining RT asymmetries and repetition priming in trilinguals. As such, it was limited in scope and could not reveal how word characteristics, such as concreteness, frequency, normative age of acquisition, or neighborhood density, might moderate the observed effects. Similarly, untangling the influences of participant characteristics would require a larger sample.

The repetition priming patterns supporting conceptmediated translation in all directions have additional implications for memory and multilingualism. The repetition priming observed for translation must have been based on speeding of the component processes, because the facilitation observed with partial repetition rules out alternative explanations, such as a route change from study to test or simple recall of the previous response. Whether the noninvolved language was covertly accessed during translation cannot be determined, but covert access had no concomitant effect on test phase performance; otherwise, the sum of FS and SE effects would have overshot the identical FE repetition effect. Finally, spoken word production ben- efited more from practice than did comprehension in word reading, which highlights the importance of production practice in $\mathrm{L} 2$ acquisition.

\section{REFERENCES}

Abunuwara, E. (1992). The structure of the trilingual lexicon. European Journal of Cognitive Psychology, 4, 311-322.

Cattell, J. M. (1947). Experiments on the association of ideas. In A. T. Poffenberger (Ed.), James McKeen Cattell, man of science: Vol. I. Psychological research (pp. 95-102). Lancaster, PA: Science Press. (Original work published 1887)

Cohen, J. D., MacWhinney, B., Flatt, M., \& Provost, J. (1993). PsyScope: An interactive graphic system for designing and controlling experiments in the psychology laboratory using Macintosh computers. Behavior Research Methods, Instruments, \& Computers, 25, 257-271.

de Groot, A. M. B., Dannenburg, L., \& van Hell, J. G. (1994). Forward and backward word translation by bilinguals. Journal of Memory \& Language, 33, 600-629.

de Groot, A. M. B., \& Hoeks, J. C. J. (1995). The development of bilingual memory: Evidence from word translation by trilinguals. Language Learning, 45, 683-724.

De Groot, A. M. B., \& KeIJzer, R. (2000). What is hard to learn is easy to forget: The roles of word concreteness, cognate status, and word frequency in foreign-language vocabulary learning and forgetting. Language Learning, 50, 1-56.

De Groot, A. M. B., \& Poот, R. (1997). Word translation at three levels of proficiency in a second language: The ubiquitous involvement of conceptual memory. Language Learning, 47, 215-264.

Durso, F. T., \& Johnson, M. K. (1979). Facilitation in naming and categorizing repeated pictures and words. Journal of Experimental Psychology: Human Learning \& Memory, 5, 449-459.

Francis, W. S., Augustini, B. K., \& Sáenz, S. P. (2003). Repetition priming in picture naming and translation depends on shared processes and their difficulty: Evidence from Spanish-English bilinguals. Journal of Experimental Psychology: Learning, Memory, \& Cognition, 29, 1283-1297.

Francis, W. S., \& SÁEnz, S. P. (2004). Repetition priming endurance in picture naming and translation: Contributions of component processes. Manuscript submitted for publication.

Francis, W. S., Tokowicz, N., \& Kroll, J. F. (2004). Translation priming in bilinguals: Effects of proficiency and item difficulty. Manuscript in preparation.

Kroll, J. F., \& Stewart, E. (1994). Category interference in translation and picture naming: Evidence for asymmetric connections between bilingual memory representations. Journal of Memory \& Language, 33, 149-174.

KuČERA, H., \& FranCIS, W. N. (1967). A computational analysis of presentday American English. Providence, RI: Brown University Press.

La Heij, W., Hooglander, A., Kerling, R., \& van der Velden, E. (1996). Nonverbal context effects in forward and backward word translation: Evidence for concept mediation. Journal of Memory \& Language, 35, 648-665.

Miller, N. A., \& Kroll, J. F. (2002). Stroop effects in bilingual translation. Memory \& Cognition, 30, 614-628.

Morris, C. D., Bransford, J. D., \& Franks, J. J. (1977). Levels of processing versus transfer appropriate processing. Journal of Verbal Learning \& Verbal Behavior, 16, 519-533.

Potter, M. C., So, K.-F., von EcKardt, B., \& Feldman, L. B. (1984). Lexical and conceptual representation in beginning and more proficient bilinguals. Journal of Verbal Learning \& Verbal Behavior, 23, 23-38.

RAAIJMAKERS, J. G. W. (2003). A further look at the "the language-asfixed-effect fallacy." Canadian Journal of Experimental Psychology, 57, 141-151.

Roediger, H. L., III, \& Blaxton, T. A. (1987). Effects of varying modality, surface features, and retention interval on priming in wordfragment completion. Memory \& Cognition, 15, 379-388. 
Sholl, A., Sankaranarayanan, A., \& Kroll, J. F. (1995). Transfer between picture naming and translation: A test of asymmetries in bilingual memory. Psychological Science, 6, 45-49.

SNODGRAss, J. G. (1993). Translating versus picture naming: Similarities and differences. In R. Schreuder \& B. Weltens (Eds.), The bilingual lexicon (pp. 83-114). Philadelphia: Benjamins.

\section{NOTES}

1. Statements about statistical significance refer to the $F_{1}$ (or $t_{1}$ ) analysis, which treats participants as the only random factor, because the authors believe that this is the most appropriate analysis (see Raaijmakers, 2003). However, we realize that this view is not universal and have provided $F_{2}\left(t_{2}\right)$ and $\min F^{\prime}$ for reference. In the $F_{2}\left(t_{2}\right)$ analyses, which treat items as the only random factor, translation direction was treated as a between-items variable, and items with missing cells were excluded. Min $F^{\prime}$, calculated as $F_{1} \times F_{2} /\left(F_{1}+F_{2}\right)$, provides a lower limit for $F^{\prime}$ when both participants and items are treated as random variables.

2. A secondary analysis in which languages were recoded on the basis of relative fluency showed asymmetries for all three comparisons $(12-21=119,23-32=289$, and $13-31=355)$ but compromised counterbalancing.

(Manuscript received February 17, 2004; revision accepted for publication March 10, 2005.) 